\title{
Effect of Materials and Techniques on Impact Strength of Reattached Anterior Fractured Teeth: An in vitro Study
}

\author{
${ }^{1}$ Minimol K Johny, ${ }^{2}$ Balaram Naik, ${ }^{3}$ Priya Horatti, ${ }^{4}$ Aravindan Devadathan, ${ }^{5}$ Baby James, ${ }^{6}$ Benley George
}

\section{ABSTRACT}

Aim: To evaluate the effects of bonding agents, composite resins, and reattachment techniques on impact strength of permanent maxillary central incisors in which fragment reattachment was done.

Materials and methods: Ninety permanent maxillary central incisors were collected and standardized fragments were obtained from 80 incisors by sectioning them $3 \mathrm{~mm}$ away from the incisal edge. The teeth specimens were distributed into eight test groups and one control group $(n=10)$ according to the reattachment technique (direct bonding or circumferential chamfer); adhesive system (single bond or Clearfil SE Bond); and intermediate material (Filtek flow or RelyX U200). The impact strength of reattached tooth was evaluated using universal testing machine Instron. The results were analyzed using one-way analysis of variance (ANOVA) and Tukey's multiple post hoc analysis.

Results: The fragment reattachment using circumferential chamfer was significantly superior to direct bonding. The use of single bond significantly increased the impact strength when compared with the use of Clearfil SE.

Conclusion: No technique or material, when individually considered, was capable of achieving the impact strength of the sound teeth; however, the association of reattachment technique circumferential chamfer with adhesive system (single bond) could approximate the impact strength of sound teeth.

Clinical significance: By achieving knowledge about the right materials and techniques for reattachment, this treatment modality could be used as a viable and feasible option for the uncomplicated fractured anterior teeth.

Keywords: Composites, Reattachment, Tooth fracture.

How to cite this article: Johny MK, Naik $B$, Horatti $P$, Devadathan A, James B, George B. Effect of Materials and Techniques on Impact Strength of Reattached Anterior Fractured Teeth: An in vitro Study. Cons Dent Endod J 2018;3(1):17-21.

\footnotetext{
${ }^{1}$ Senior Lecturer, ${ }^{2-5}$ Professor, ${ }^{6}$ Reader and Head

1,4,5 Department of Conservative Dentistry and Endodontics Pushpagiri College of Dental Sciences, Thiruvalla, Kerala, India

${ }^{2,3}$ Department of Conservative Dentistry and Endodontics, Sri Dharmasthala Manjunatheshwara College of Dental Sciences \& Hospital, Dharwad, Karnataka, India

${ }^{6}$ Department of Public Health Dentistry, Pushpagiri College of Dental Sciences, Thiruvalla, Kerala, India

Corresponding Author: Minimol K Johny, Senior Lecturer Department of Conservative Dentistry and Endodontics Pushpagiri College of Dental Sciences, Thiruvalla, Kerala, India Phone: +919048820602, e-mail: minimolkjohny@gmail.com
}

\section{Source of support: Nil}

Conflict of interest: None

\section{INTRODUCTION}

Traumatic fracture of maxillary anterior teeth is the most frequent type of injury in the permanent dentition, in children of age 9 to 11 years. ${ }^{1-4}$ Though there are several direct and indirect techniques for restoring fractured teeth, they are not conservative, are time consuming and expensive. ${ }^{1}$

The development of adhesive materials and techniques has made reattachment a viable technique and should be considered as the first choice to restore fractured teeth, if the fractured fragment is retrieved intact. ${ }^{5}$ Fragment bonding has several advantages over other techniques which include: (a) Superior natural appearance; (b) harmonious wear; (c) preservation of the pulp vitality; and (d) economical and less time consuming. ${ }^{4,6}$

Several techniques have been proposed for reattaching the fragment to the remaining tooth: Simple reattachment using only adhesive systems; ${ }^{7-9}$ simple reattachment using an adhesive system and an intermediate material;,5-11 enamel beveling before the reattachment; ${ }^{10,12}$ external chamfer (circumferential or partial) in the fracture line after the reattachment; ${ }^{5,9,13} \mathrm{~V}$-shaped internal enamel groove; internal dentin groove; ${ }^{5,9,12}$ complete removal of dentin from the fragment before reattachment; ${ }^{14}$ and overcontouring with a thin composite resin layer. $3,5,9$

Esthetic recovery is the main advantage of simple reattachment technique using adhesive system with or without intermediate material and without additional preparation. But the possibility of debonding is higher. ${ }^{5,10}$ The chamfer technique of creating the chamfer in the fracture line after performing the bonding procedure was developed to overcome the adaptation problem between the segments, which is the main disadvantage of beveling technique. ${ }^{1}$

Various adhesive systems also can be efficiently used for tooth fragment reattachment. Pagliarini et $\mathrm{al}^{8}$ observed that fractured teeth reattached with conventional totaletch (TE) adhesive system showed higher fracture strength than self-etching (SE) systems. Conversely, Sengun et $\mathrm{al}^{15}$ found no significant difference between the use of SE and TE adhesive systems in cases of fragment reattachment. 
Currently light-, dual-, or self-cured luting cements, as well as conventional or flowable composite resins, have been proposed to be used as intermediate materials which can improve the mechanical properties of the interface, with some influence on the impact strength of the restored teeth. ${ }^{16}$

There is dearth of literature pertaining to the effect of different materials and reattachment techniques on impact strength of human permanent maxillary anterior teeth. Thus the present study was conducted to evaluate the effect of different materials and reattachment techniques on the impact strength of human permanent maxillary central incisors in which fragment reattachment was done. We hypothesized that association of reattachment technique, adhesive system, and intermediate material can recover the impact strength of fragment reattached teeth comparable to the sound teeth.

\section{MATERIALS AND METHODS}

\section{Sample Selection}

This study utilized freshly extracted human permanent maxillary central incisors $(n=90)$. Only sound teeth without any fracture or craze lines were selected for the study. The teeth specimens were stored in $0.5 \%$ chloramine $\mathrm{T}$ solution. Crowns of 80 teeth were sectioned $3 \mathrm{~mm}$ from the incisal edge using diamond disk and straight hand-piece to obtain standardized fragments. The section was done perpendicular to the long axis of the teeth and parallel to the incisal edge. The sectioned teeth were divided into eight test groups $(n=10)$ according to employed materials (adhesive system and luting agent) and reattachment technique used. The control group comprised of sound teeth $(n=10)$. The detailed procedures for fragment reattachment for each group are described below.

\section{Group I (GI)}

Single-bond adhesive system (3M/ESPE) was applied according to manufacturer's directions on the fractured surfaces of the fragment and fractured tooth after etching with phosphoric acid $\left(\mathrm{H}_{3} \mathrm{PO}_{4}\right)$ (Scotchbond Etchant; $3 \mathrm{M}$ / ESPE). The adhesive was light cured for 20 seconds using Bluedent light-emitting diode (LED) light, with irradiance of $700 \mathrm{~mW} \mathrm{~cm}^{2}$. The restorative composite resin Filtek flow (3M/ESPE) was applied on the fractured surface of the tooth, and the fragment was positioned (direct bonding). After fragment positioning, the light curing was carried out in four stages: 20 seconds each for mesio-labial half, disto-labial half, mesio-palatal half, and disto-palatal half.

\section{Group II (GII)}

Self-etch adhesive system Clearfil SE Bond (Kuraray Co., Tokyo, Japan) was used in GII. Self-etching primer and bonding agent was applied on fractured surfaces of fragment and fractured tooth according to the manufacturer's instructions and light cured for 20 seconds using Bluedent LED light, with irradiance $700 \mathrm{~mW} \mathrm{~cm}^{2}$. Then, the fragment was directly bonded using the composite resin Filtek flow, as described for GI.

\section{Group III (GIII)}

Single-bond adhesive system was applied as described for GI. Then, the dual resin cement RelyX U200 (3M/ ESPE) was used as the intermediate material for directly bonding the fragment with the fractured tooth. Light curing procedures were performed in the same way as described in GI.

\section{Group IV (GIV)}

Self-etch adhesive system Clearfil SE Bond was applied as described in GII. Then, the dual resin cement RelyX U200 was applied as described in GIII.

\section{Group V (GV), Group VI (GVI), Group VII (GVII), and Group VIII (GVIII)}

In all these groups, reattachment of fractured fragment was done as described in the above groups (GI-GIV). A summary of reattachment protocol is given in Table 1.

After reattachment, a 2-mm depth circumferential chamfer was placed in the fracture line using a round diamond point, in all the teeth belonging to GV, GVI, GVII, and GVIII. The chamfer was restored using the single-bond adhesive system, according to manufacturer's directions and Filtek Z250 (3M/ESPE).

\section{GC-Control group-Sound Teeth $(n=10)$}

Finishing and polishing were done along the reattached labial and palatal surface using Sof-Lex system (3M/ ESPE) for all the reattached teeth specimens. They were further stored in an incubator for 24 hours at $37^{\circ} \mathrm{C}$ and $100 \%$ humidity until subjected to impact strength analysis.

For impact strength evaluation, all the 90 teeth were individually mounted in self-cure acrylic resin up to the level of cementoenamel junction. To evaluate the resistance

Table 1: Summary of reattachment protocol of all groups

\begin{tabular}{lllll}
\hline & Direct & & \multicolumn{2}{l}{ Circumferential chamfer } \\
\hline Materials & Filtek flow & RelyX & Filtek flow & RelyX \\
Single bond & GI & GIII & GV & GVII \\
Clearfil SE bond & GII & GIV & GVI & GVIII \\
\hline
\end{tabular}


to impact, specimens were positioned in a universal testing machine using a stainless steel jig with $70 \mathrm{~mm}$ height, and a square base of $70 \times 70 \mathrm{~mm}$ and $\mathrm{a} 45^{\circ}$ inclined plane with a central hole (21 mm in diameter and $20 \mathrm{~mm}$ of depth). The teeth were then submitted to a tangential load at 5 $\mathrm{mm} / \mathrm{min}$ crosshead speed. The load cell used was $500 \mathrm{~kg}$ $(5,000 \mathrm{~N})$. The antagonistic metallic device was fixed to the universal testing machine and positioned $1 \mathrm{~mm}$ from the incisal edge of the labial surfaces of the teeth. The load required to fracture the specimens was recorded (kgf) and data were subjected to one-way ANOVA and Tukey's multiple post hoc analysis. The level of significance was set as $\mathrm{p}<0.05$.

\section{RESULTS}

For impact strength evaluation, maximum load required to fracture the teeth specimen was recorded using universal strength testing machine. The values were obtained in terms of kgf (Graph 1).

Circumferential chamfer technique (GV-GVIII) provided higher impact strength mean than the direct bond technique (GI-GIV) (Graph 1). However, both techniques showed lower impact strength than the control group (Graph 1).

There also was a significant difference among single bond and Clearfil SE Bond (Table 2, p<0.05). Groups in

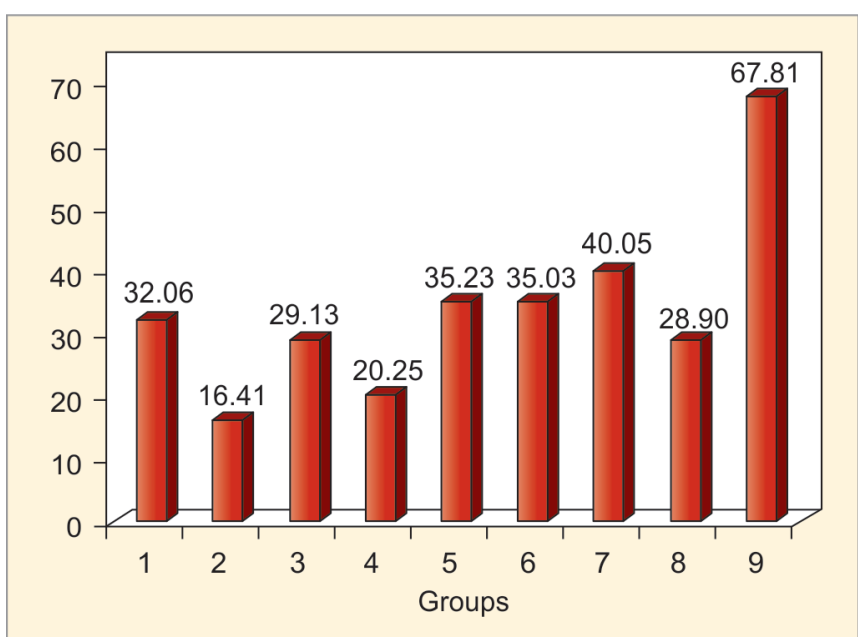

Graph 1: Comparison of nine groups (GI, GII, GIII, GIV, GV, GVI, GVII, GVIII, and control) with respect to impact strength means

Table 2: Comparison of eight groups (GI, GII, GIII, GIV, GV, GVI, GVII, control) with respect to impact strength scores

\begin{tabular}{lcllll}
\hline & DF & $\begin{array}{l}\text { Sum of } \\
\text { squares }\end{array}$ & $\begin{array}{l}\text { Mean sum } \\
\text { of squares }\end{array}$ & $f$-value & $p$-value \\
\hline $\begin{array}{l}\text { Between } \\
\text { groups }\end{array}$ & 8 & 17337.2629 & 2167.1579 & 928.0916 & $0.0000^{*}$ \\
$\begin{array}{l}\text { Within } \\
\text { groups }\end{array}$ & 81 & 189.1406 & 2.3351 & & \\
\hline Total & 89 & 17526.4035 & & & \\
\hline${ }^{*} p<0.05$, one-way ANOVA test & & & \\
\hline
\end{tabular}

which single-bond bonding agent was used (GI, GIII, GV, GVII) provided higher means than the corresponding Clearfil SE Bond groups (GII, GIV, GVI, and GVIII) (Graph 1). However, both adhesive systems showed lower impact strength than the control group (Graph 1).

However, there was no consistent difference among the impact strength mean values for Filtek flow (GI, GII, GV, and GVI) and RelyX U 200 (GIII, GIV, GVII, and GVIII-Table 2).

\section{DISCUSSION}

Currently reattachment is a viable technique and should be considered as the first choice to restore fractured teeth, if the fractured fragment is retrieved intact. Maxillary anterior teeth were selected for the study because of the high frequency of trauma in this region. ${ }^{2-4}$ and most of the reattachment failures occur due to new trauma. ${ }^{4}$ So, by increasing the impact strength of reattached teeth by using different methods, longevity of the restoration could be increased.

In order to evaluate the impact strength, universal strength testing machine (Instron) was used in such a way as described in methodology to simulate impact from a fall. From the study, it was observed that the reattachment technique plays a major role in determining the impact strength; the type of adhesive system shows a secondary, but significant, influence; and type of intermediate material has no significant influence on impact strength of reattached teeth.

Impact strength mean values of all experimental groups (Graph 1) show that circumferential chamfer technique (GV-GVIII) is more effective than the direct bonding technique (GI-GIV). These results corroborate with those found by Demarco et al. ${ }^{10}$ During chamfer preparation, enamel prisms are altered, thus the bonding area is increased which allows higher bond strength of the fragment to the fractured surface of the tooth. Also, bonding line appeared stronger when chamfer was filled with composite resin material of superior mechanical properties than direct bonding. ${ }^{10}$

Another parameter analyzed in this study was the adhesive system and statistically significant difference was observed between both adhesive systems. The TE adhesive system single bond provided higher impact strength mean values than the SE adhesive system Clearfil SE Bond (Graph 1). Enamel etching with phosphoric acid in TE provides selective dissolution of prisms, increasing porosity and surface energy, allowing better surface wetting by the adhesive and better interlocking between adhesive and substrate. ${ }^{17}$ With SE adhesives, the pattern of enamel etching is less favorable for bonding. ${ }^{10}$ The primer of Clearfil SE Bond contains acidic monomers, 
such as unsaturated methacrylate phosphate monoester, 10-methacryloxydecyl dihydrogen phosphate, in a concentration of 25 to $30 \%$. Di Hipolito et $\mathrm{al}^{17}$ observed that the enamel etching produced by the SE primer is less aggressive, which can result in superficial interaction with enamel and lower potential for micromechanical interlocking when compared with the phosphoric acid treatment. The differences in enamel etching pattern may be due to $\mathrm{pH}$ difference of the systems. Phosphoric acid $\mathrm{pH}$ is 0.5 (according to the manufacturer), whereas $\mathrm{pH}$ of SE primer of Clearfil SE Bond (2.3) is higher than that of phosphoric acid, so that effective dissolution of enamel prisms does not occur. However, the use of SE adhesive systems may be considered when the dentin that exposed the fracture site is very close to the pulp, which could reduce the technique sensitivity and risk of postoperative sensitivity. ${ }^{18,19}$

It was observed that the intermediate materials had no direct influence on impact strength, corroborating the findings of Farik et al. ${ }^{16}$ There was no significant difference between the dual-cure luting cement RelyX U200 groups and the restorative composite resin Filtek flow groups. It probably has occurred because both materials have similar mechanical properties and close approximation of the fractured fragments appeared to be more important than the intermediate material.

In the study, it was observed that an appropriate combination of reattachment technique and adhesive system can completely rehabilitate the reattached teeth, providing impact strength comparable to sound teeth. Among the test groups, the highest mean impact strength could be observed in GVII and GV, which showed 71.5 and $58.3 \%$ of that of control group, which denotes that combination of circumferential chamfer technique and TE adhesive system (single bond) could provide impact strength comparable to sound teeth.

The lowest impact strength values were found when the association between direct bonding technique and SE adhesive system was used (GII and GIV); GII and GIV showed significantly reduced impact strength values when compared with GV, GVII, and control group, which is suggestive of higher risk of debonding.

Based on the results of this study, it was observed that the reattachment technique and proper selection of adhesive materials are the main factors that determine the impact strength of fragment reattached teeth. However, the bonding procedure is also important and should be carried out carefully, because flaws during the bonding procedure could reduce the bond strength of the segments. However, studies evaluating thermal and mechanical challenges on the fragment reattached teeth simulating clinical conditions are necessary to predict the longevity of this treatment modality.

\section{CONCLUSION}

The following conclusions could be drawn from the results of the present study:

- Reattachment technique is the main determinant of impact strength of fragment reattached teeth. Circumferential chamfer technique showed better results than direct bonding technique.

- Adhesive system selection has secondary, but significant effect on impact strength of fragment reattached teeth. Total-etch adhesive system (single bond) showed better results than SE system (Clearfil SE Bond).

- Impact strength of fragment reattached teeth is not influenced by intermediated material. Filtek flow and RelyX U200 showed similar results.

- Only the association of reattachment technique using circumferential chamfer with the TE adhesive system single bond could approximate the impact strength of the fragment reattached teeth to that achieved by sound teeth.

\section{CLINICAL SIGNIFICANCE}

By achieving knowledge about the right materials and techniques for reattachment, this treatment modality could be used as a viable and feasible option for the uncomplicated fractured anterior teeth.

\section{REFERENCES}

1. Bruschi-Alonso RC, Bruschi Alonso RC, Correr GM, Alves CM, Lewgoy HR, Sinhoreti MA, Puppin-Rontani RM, CorrerSobrinho L. Reattachment of anterior fractured teeth: effect of materials and techniques on impact strength. Dent Traumatol 2010 Aug;26(4):315-322.

2. Tovo MF, dos Santos PR, Kramer PF, Feldens CA, Sari GT. Prevalence of crown fractures in 8-10 years old schoolchildren in Canoas, Brazil. Dent Traumatol 2004 Oct;20(5):251254.

3. Zuhal K, Semra OE, Huseyin K. Traumatic injuries of the permanent incisors in children in southern Turkey: a retrospective study. Dent Traumatol 2005 Feb;21(1):20-25.

4. Reis A, Loguercio AD, Kraul A, Matson E. Reattachment of fractured teeth: a review of literature regarding techniques and materials. Oper Dent 2004 Mar-Apr;29(2):226-233.

5. Reis A, Francci C, Loguercio AD, Carrilho MR, Rodriques Filho LE. Reattachment of anterior fractured teeth: fracture strength using different techniques. Oper Dent 2001 MayJun;26(3):287-294.

6. Terry DA. Adhesive reattachment of a tooth fragment: the biological restoration. Pract Proced Asthet Dent 2003 Jun;15(5):403-409.

7. Farik B, Munksgaard EC. Fracture strength of intact and fragment-bonded teeth at various velocities of the applied force. Eur J Oral Sci 1999 Feb;107(1):70-73.

8. Pagliarini A, Rubini R, Rea M, Campese M. Crown fractures: effectiveness of current enamel-dentin adhesives in reattachment of fractured fragments. Quintessence Int 2000 Feb;31(2):133-136.

9. Loguercio AD, Mengarda J, Amaral R, Kraul A, Reis A. Effect of fractured or sectioned fragments on the fracture strength 
of different reattachment techniques. Oper Dent 2004 MayJun;29(3):295-300.

10. Demarco FF, Fay RM, Pinzon LM, Powers JM. Fracture resistance of re-attached coronal fragments-influence of different adhesive materials and bevel preparation. Dent Traumatol 2004 Jun;20(3):157-163.

11. Farik B, Munksgaard EC, Andreasen JO. Impact strength of teeth restored by fragment-bonding. Endod Dent Traumatol 2000 Aug;16(4):151-153.

12. Worthington RB, Murchison DF, Vandewalle KS. Incisal edge reattachment: the effect of preparation utilization and design. Quintessence Int 1999 Sep;30(9):637-643.

13. Andreasen FM, Noren JG, Andreasen JO, Engelhardtsen S, Lindh-Stromberg U. Long-term survival of fragment bonding in the treatment of fractured crowns: a multicenter clinical study. Quintessence Int 1995 Oct;26(10):669-681.

14. Capp CI, Roda MI, Tamaki R, Castanho GM, Camargo MA, de Cara AA. Reattachment of dehydrated dental fragment using two techniques. Dent Traumatol 2009 Feb;25(1): 95-99.

15. Sengun A, Ozer F, Unlu N, Ozturk B. Shear bond strengths of tooth fragments reattached or restored. J Oral Rehabil 2003 Jan;30(1):82-86.

16. Farik B, Munksgaard EC, Suh BI, Andreasen JO, Kreiborg S. Adhesive bonding of fractured anterior teeth: effect of wet technique and rewetting agent. Am J Dent 1998 Dec;11(6):251-253.

17. Di Hipolito V, de Goes MF, Carrilho MR, Chan DC, Daronch M, Sinhoreti MA. SEM evaluation of contemporary selfetching primers applied to ground and unground enamel. J Adhes Dent 2005 Autumn;7(3):203-211.

18. Hannig M, Reinhardt KJ, Bott B. Self-etching primer vs phosphoric acid: an alternative concept for composite-to enamel bonding. Oper Dent 1999 May-Jun;24(3):172-180.

19. Sano H, Takatsu T, Ciucchi B, Horner JA, Matthews WG, Pashley DH. Nanoleakage: leakage within the hybrid layer. Oper Dent 1995 Jan-Feb;20(1):18-25. 